\title{
Identical twins with differing forms of ventricular pre-excitation
}

\author{
D. H. BENNETT, B. GRIBBIN, AND J. S. BIRKHEAD \\ From the Cardiac Department, Radcliffe Infirmary, Oxford and the General Hospital, Northampton
}

SUMMARY Identical 10-year-old twins, both with electrocardiograms showing a short PR interval and a normal QRS complex but with dramatically different electrophysiological characteristics, are described.

One twin experienced episodes of rapid palpitation and on one occasion was resuscitated from ventricular fibrillation. An intracardiac electrophysiological study confirmed the presence of an atrioventricular nodal bypass tract and in addition revealed the presence of an accessory atrioventricular pathway, thus demonstrating that the patient had both the Lown-Ganong-Levine and Wolff-ParkinsonWhite syndromes. Re-entry tachycardia and atrial fibrillation, with a very rapid ventricular rate, were precipitated. After treatment with amiodarone, the patient became asymptomatic and a repeat study showed that the features of the atrioventricular nodal bypass tract were no longer present and though re-entry tachycardias using the accessory atrioventricular pathway could still be induced, their rates were slower than before treatment.

The other twin, in spite of an identical surface electrocardiogram, was asymptomatic. An electrophysiological study showed the features of an atrioventricular nodal bypass tract but there was no evidence of additional atrioventricular accessory connections and a tachycardia could not be induced.

The Lown-Ganong-Levine syndrome (1952) and the Wolff-Parkinson-White syndrome (1930) are both types of ventricular pre-excitation. The former results from an atrioventricular nodal bypass tract and the latter from an accessory atrioventricular pathway (Wellens, 1975).

The purpose of this paper is to describe identica! twins with differing forms of pre-excitation. Both have the surface and intracardiac electrophysiological features of an atrioventricular nodal bypass tract (Lown-Ganong-Levine syndrome). One twin has in addition, the features of a concealed accessory atrioventricular pathway (Wolff-Parkinson-White syndrome). In cases of ventricular pre-excitation, accessory atrioventricular connections of more than one type are sometimes present but this is only the second report of a patient with the surface electrocardiogram of the Lown-Ganong-Levine syndrome in whom an accessory atrioventricular pathway was disclosed by an intracardiac electrophysiological study (Massumi and Vera, 1971; Spurrell et al., 1973; Gallagher et al., 1976), and it is the first report of identical twins with proved atrioventricular nodal bypass tracts.

Received for publication 26 September 1977

\section{Patients and methods}

The patients are identical, male, 10-year-old twins. They were born after an uncomplicated pregnancy and delivery but twin A was noticed to have an apical systolic murmur in infancy and this has persisted. Twin A had experienced frequent, brief episodes of rapid palpitation for some months before the incident which brought about his admission to hospital. At that time his father, a general practitioner, found that he had a heart rate of over 300 per minute; carotid sinus massage was ineffective and 2 hours later, after admission, an electrocardiogram showed atrial fibrillation with an extremely rapid ventricular rate (Fig. 1A). Shortly afterwards he developed ventricular fibrillation and was rapidly defibrillated. Twin B was asymptomatic. Both boys had identical surface electrocardiograms showing a short PR interval, and a normal QRS complex and QT interval (Fig. 1B). Chest radiographs and echocardiograms of both twins were normal as were the electrocardiograms of first degree relatives.

Because of the heart murmur, cardiac catheterisation was performed on twin $A$ and both twins had intracardiac electrophysiological studies under local anaesthesia after premedication with diazepam and 


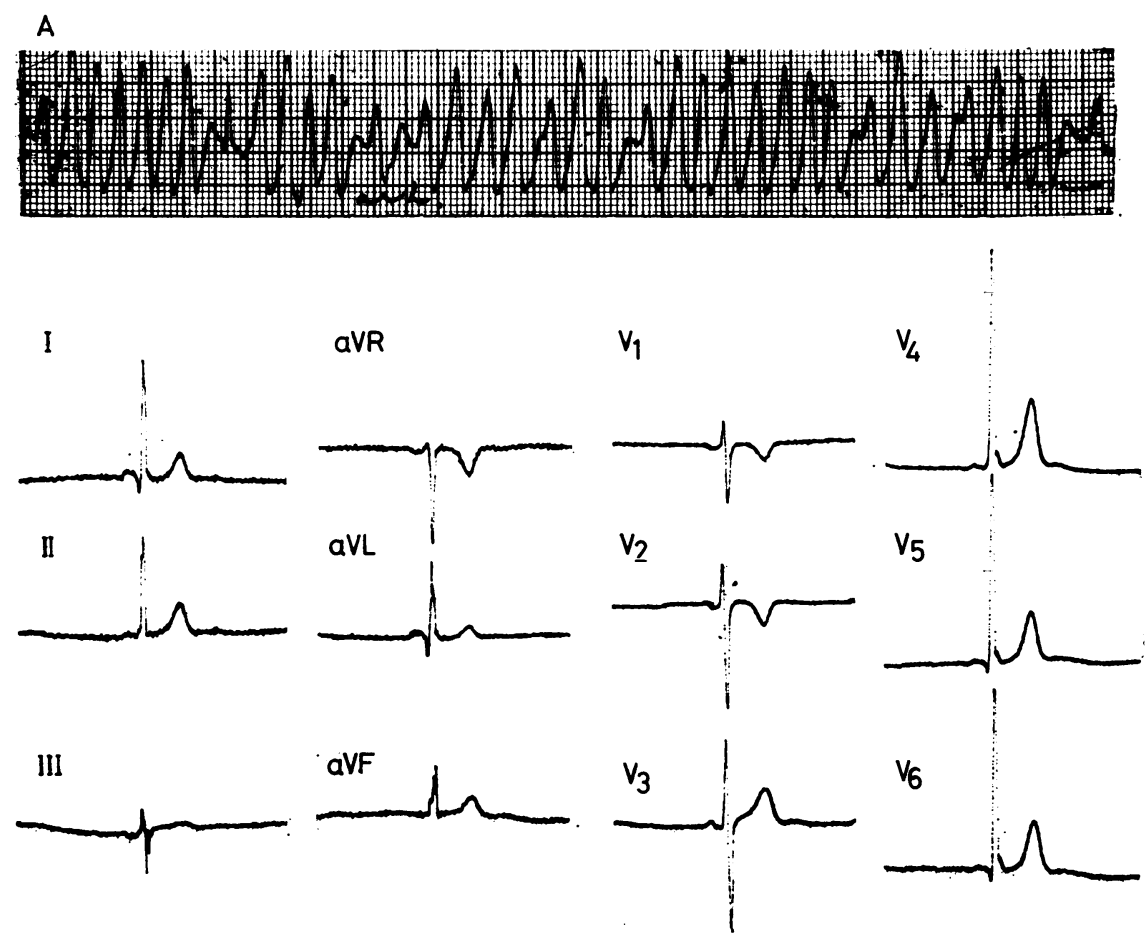

B

Fig. 1 (A) Twin A: electrocardiogram on admission showing atrial fibrillation, minimum $R R$ interval $130 \mathrm{~ms}$. (B) The twins had identical electrocardiograms, $P R, 100 \mathrm{~ms}$.

droperidol. At the time of the initial study no other drugs were being taken. Twin A was restudied after 5 weeks' treatment with amiodarone $(600 \mathrm{mg}$ daily for 3 weeks and then $400 \mathrm{mg}$ daily). In each study a quadripolar and a tripolar electrode were introduced percutaneously from the right femoral vein. The quadripolar electrode was advanced to the right atrium, the distal poles were used for recording the high right atrial electrogram and the proximal poles for atrial stimulation. The tripolar electrode was positioned across the tricuspid valve to record the low right atrial and His bundle electrograms, and was also advanced into the right ventricle for ventricular stimulation. Two limb leads and lead V1 were also recorded. Recordings were made simultaneously on an ink jet recorder at a paper speed of $100 \mathrm{~mm} / \mathrm{s}$. The initial electrophysiological study on twin A was performed after the haemodynamic study and time permitted only a brief examination; for this reason, only atrial and ventricular pacing at varying rates was done, whereas in the study on twin $B$ and in the second study on twin A both rapid pacing and programmed premature stimulation were carried out.

\section{Results}

\section{TWIN A}

Right and left heart pressures and oxygen saturations, and a left ventricular angiocardiogram were normal; no cause for the systolic murmur was found.

The results of the first electrophysiological study are summarised in Table 1. Atrioventricular nodal

Table 1 Twin A: conduction times during sinus rhythm and atrial pacing

\begin{tabular}{|c|c|c|c|c|c|c|}
\hline & & $\begin{array}{l}\text { Rate } \\
\text { (beats/min) }\end{array}$ & $\begin{array}{l}A H \\
\text { (ms) }\end{array}$ & $\begin{array}{l}H V \\
(m s)\end{array}$ & \multicolumn{2}{|c|}{ QRS complex } \\
\hline \multicolumn{2}{|c|}{$\begin{array}{l}\text { Sinus rhythm } \\
\text { Atrial pacing }\end{array}$} & 125 & \multirow{2}{*}{$\begin{array}{l}50 \\
50 \\
50\end{array}$} & $\begin{array}{l}35 \\
35\end{array}$ & \multicolumn{2}{|c|}{ Normal } \\
\hline " & " & \multirow{2}{*}{$\begin{array}{l}170 \\
188\end{array}$} & & 35 & \multicolumn{2}{|l|}{ " } \\
\hline ", & , & & \multirow{2}{*}{$\begin{array}{l}60 \\
60\end{array}$} & 35 & \multicolumn{2}{|l|}{$\because$} \\
\hline " & ", & 200 & & 35 & \multicolumn{2}{|l|}{ 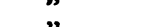 } \\
\hline , & ", & \multirow{2}{*}{$\begin{array}{l}222 \\
240\end{array}$} & 60 & 35 & \multicolumn{2}{|l|}{$"$} \\
\hline " & " & & 70 & 20 & \multicolumn{2}{|c|}{ Delta wave } \\
\hline و & " & \multirow{2}{*}{$\begin{array}{l}260 \\
285\end{array}$} & \multirow{2}{*}{\multicolumn{2}{|c|}{ lection not identified }} & ," & , \\
\hline " & " & & & & " & ", \\
\hline
\end{tabular}


conduction time (AH interval) was short and increased only minimally with rapid atrial pacing (Fig. 2A) indicating an atrioventricular nodal bypass tract (Castellanos et al., 1971; Caracta et al., 1973; Gallagher et al., 1976). His-Purkinje conduction time (HV interval) was normal. At atrial pacing rates of 240 per minute and greater, the QRS complexes became deformed and the $\mathrm{HV}$ interval shortened by the appearance of a delta wave, positive in lead V1 (Fig. 2B) thus showing the presence of either a concealed accessory atrioventricular pathway, or possibly a nodoventricular or fasciculoventricular accessory connection (Mahaim fibres). 1:1 atrioventricular conduction was maintained at the highest rate, 285 per minute, at which the atria were paced. Right ventricular pacing, performed at rates up to 230 per minute, resulted in a constant ventriculoatrial conduction time (VA interval) of $110 \mathrm{~ms}$. Re-entry tachycardia (250 per minute) and atrial fibrillation with virtually all complexes show-

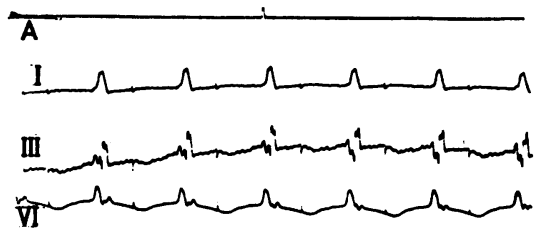

ing type A pre-excitation (minimum interval between pre-excited ventricular complexes $170 \mathrm{~ms}$ ) each occurred several times during the investigation (Fig. 2C, D).

The results of the second study are summarised in Table 2. Amiodarone prolonged the PR $(130 \mathrm{~ms})$,

Table 2 Twin $A$ after amiodarone: conduction times during sinus rhythm and atrial pacing

\begin{tabular}{|c|c|c|c|c|c|c|}
\hline & & $\begin{array}{l}\text { Rate } \\
\text { (beats/min) }\end{array}$ & $\begin{array}{l}A H \\
(m s)\end{array}$ & $\begin{array}{l}H V \\
\text { (ms) }\end{array}$ & \multicolumn{2}{|c|}{$Q R S$ complex } \\
\hline \multicolumn{2}{|c|}{$\begin{array}{l}\text { Sinus rhythm } \\
\text { Atrial pacing }\end{array}$} & \multirow{9}{*}{$\begin{array}{r}83 \\
100 \\
120 \\
140 \\
150 \\
170 \\
188 \\
200 \\
210 \\
220\end{array}$} & \multirow{9}{*}{$\begin{array}{l}70 \\
80 \\
100 \\
135 \\
140 \\
200 \\
205 \\
210 \\
230 \\
2: 1 \text { a }\end{array}$} & \multirow{9}{*}{$\begin{array}{r}35 \\
35 \\
35 \\
10 \\
0 \\
-50 \\
-55 \\
-60 \\
-70 \\
\text { block }\end{array}$} & \\
\hline & , & & & & \multirow{2}{*}{\multicolumn{2}{|c|}{ Delta wave }} \\
\hline " & " & & & & & \\
\hline ", & ", & & & & , & ," \\
\hline " & " & & & & $"$ & $"$ \\
\hline " & " & & & & " & " \\
\hline ", & ", & & & & ", & ", \\
\hline$"$ & " & & & & $"$ & " \\
\hline 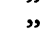 & " & & & & & \\
\hline
\end{tabular}

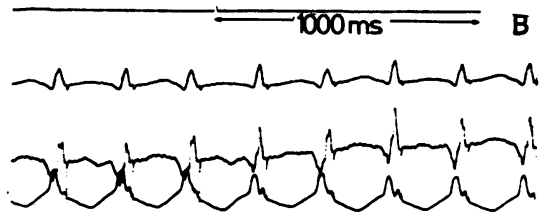

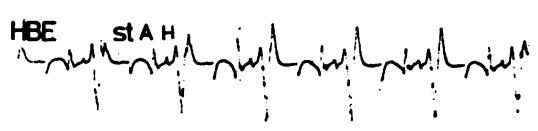

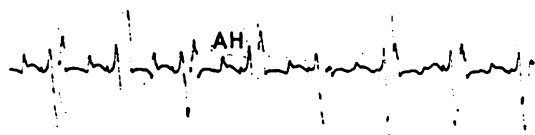
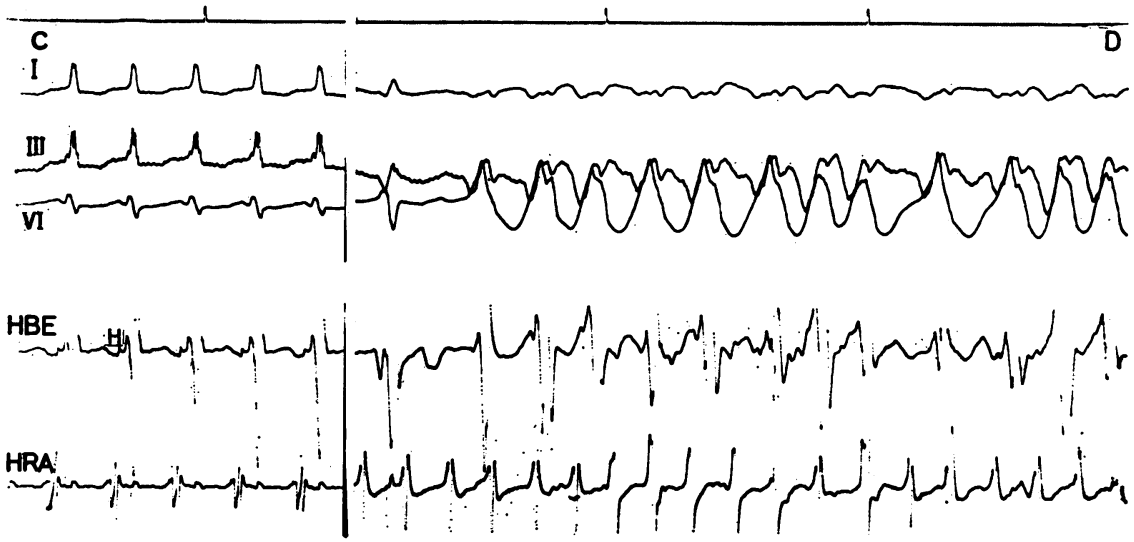

Fig. 2 Twin A: $(A)$ atrial pacing at 188 per minute, $A H, 60$ ms, note the distinct atrial latency period; $(B)$ atrial pacing at 240 per minute led to the appearance of delta waves, $A H, 70 \mathrm{~ms}$; (C) re-entry tachycardia, rate 250 per minute; (D) atrial fibrillation, minimum $R R$ interval $170 \mathrm{~ms}$, conduction mainly via accessory atrioventricular pathway.

$H B E$ and $H R A$, His bundle and high right atrial electrograms, respectively; st, pacing stimulus; $A$ and $H$, atrial and His bundle depolarisation respectively. 
$\mathrm{AH}(70 \mathrm{~ms})$ and $\mathrm{QT}\left(\mathrm{QT}_{\mathfrak{c}} 420 \mathrm{~ms}\right)$ intervals. In contrast to the first study, distinct increases in the $\mathrm{AH}$ interval occurred with rapid atrial pacing and with single premature atrial stimuli. Thus, the features of an atrioventricular nodal bypass tract were no longer present. However, atrial pacing at rates of 140 per minute and greater, and single atrial stimuli within $440 \mathrm{~ms}$ of the preceding atrial beat led to the appearance of a delta wave (Fig. 3A). As the cycle length was shortened, the delta waves, which had similar vectors to those seen in the first study, became progressively larger and the HV interval became progressively shorter. These are the features of an accessory atrioventricular pathway rather than Mahaim fibres (Wellens, 1975; Gallagher et al., 1976). Re-entry tachycardia using the accessory atrioventricular pathway in both anterograde (225 per minute) and retrograde (167 per minute) directions occurred but their rates were considerably less than found in the first study and $C$ atrial fibrillation did not occur (Fig. 3B, C). Twin $\mathrm{A} \underset{\mathrm{F}}{\overrightarrow{5}}$ has been asymptomatic in the 8 months sinceamiodarone was started.

TWIN B

The results are summarised in Table 3. During $\frac{\mathbb{\Omega}}{\stackrel{2}{2}}$ sinus rhythm values for the $\mathrm{AH}$ and $\mathrm{HV}$ intervals ${ }^{\text {s }}$ were the same as in Twin A. On rapid atrial pacing. and with single premature atrial stimuli small $=$ increases in AH interval occurred, but even at ${ }_{\sigma}^{\omega}$ 230 per minute, the maximum rate at which $1: 1 \mathrm{AV}$ conduction was maintained, the $\mathrm{AH}$ interval had increased by only $65 \mathrm{~ms}$. Even at the shortest cycle length delta waves did not appear. Right ventricular: pacing up to 200 per minute resulted in a constant $\stackrel{+}{*}$ VA interval of $110 \mathrm{~ms}$; above this rate $2: 1$ ventriculo-O atrial block occurred. These findings indicate anatrioventricular nodal bypass tract but there was no
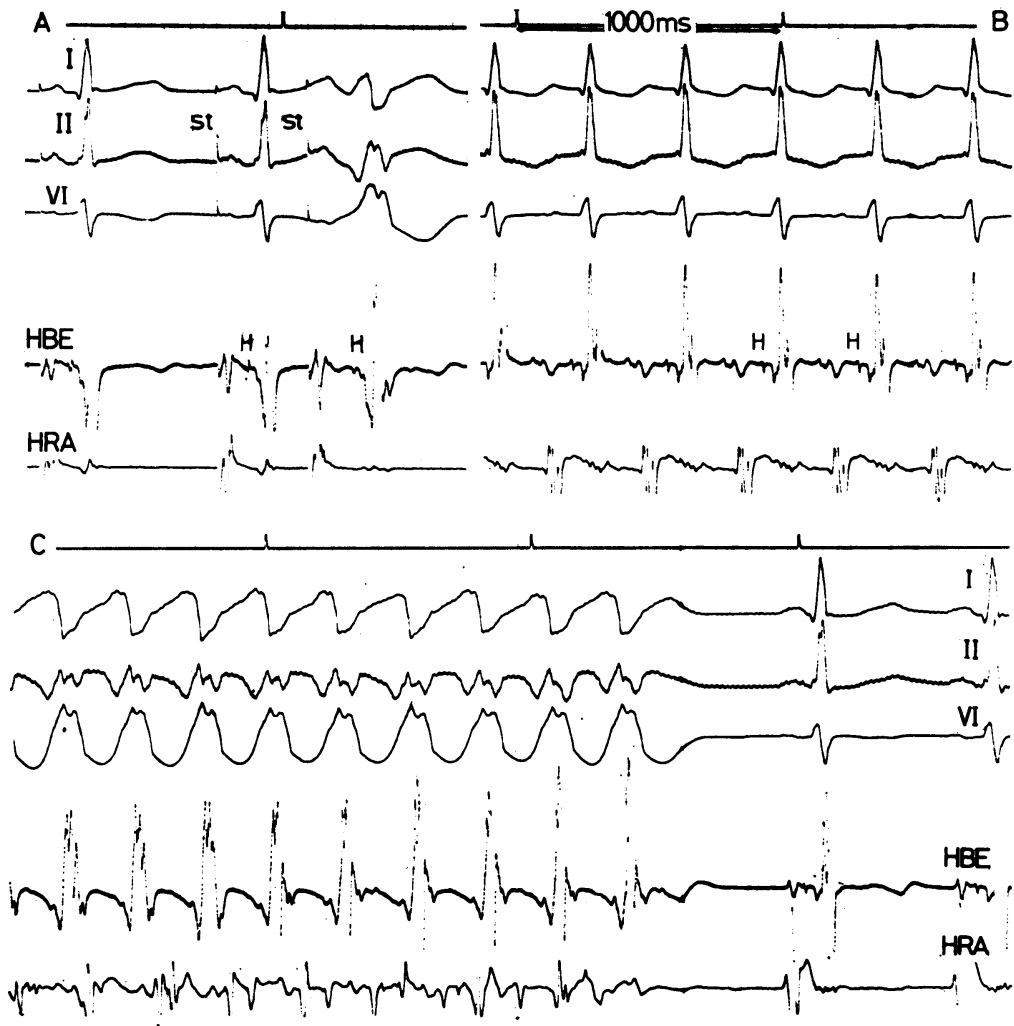

Fig. 3 Twin $A$ after amiodarone: $(A)$ premature atrial stimulus at $340 \mathrm{~ms}$ prolonged $A H$ to $150 \mathrm{~ms}$ and produced delta wave; $(B)$ re-entry tachycardia, rate 167 per minute, using accessory atrioventricular pathway in retrograde direction; $(C)$ re-entry tachycardia, rate 225 per minute, using accessory atrioventricular pathway in anterograde direction, spontaneously reverting to sinus rhythm. 
Table 3 Twin B: conduction times during sinus rhythm and atrial pacing

\begin{tabular}{|c|c|c|c|c|c|}
\hline & & $\begin{array}{l}\text { Rate } \\
\text { (beats/min) }\end{array}$ & $\begin{array}{l}A H \\
(m s)\end{array}$ & $\begin{array}{l}H V \\
(m s)\end{array}$ & QRS complex \\
\hline \multicolumn{2}{|c|}{ Sinus rhythm } & 103 & 50 & 35 & Normal \\
\hline \multicolumn{2}{|c|}{ Atrial pacing } & 110 & 50 & 35 & , \\
\hline \multirow{2}{*}{ ", } & , & 130 & 60 & 35 & , \\
\hline & , & 150 & 80 & 35 & " \\
\hline " & $"$ & 170 & 90 & 35 & " \\
\hline \multirow{2}{*}{ ", } &, & 190 & 95 & 35 & " \\
\hline & , & 200 & 100 & 35 & ", \\
\hline " & , & 220 & 110 & 35 & ", \\
\hline \multirow{2}{*}{ ", } & ", & 230 & 115 & 35 & ", \\
\hline & , & 240 & 115 & $2: 1$ ir & isian block \\
\hline$"$ & ", & 250 & $2: 1 \mathrm{~s}$ & lisian $t$ & \\
\hline
\end{tabular}

evidence of an accessory atrioventricular pathway. A tachycardia could not be precipitated by either premature atrial or ventricular stimulation.

\section{Discussion}

It has been known for many years that the WolffParkinson-White syndrome can occur in several members of a family, and it has been reported in a set of identical twins (Wolff et al., 1930; Oehnell, 1944; McIntire and Freed, 1955; Harnischfeger, 1959; Massumi, 1967; Schneider, 1969). There are, however, only 2 reports of a familial incidence of the Lown-Ganong-Levine syndrome. Lown et al. (1952) mentioned a mother and son with the disorder and recently Brodsky et al. (1977) described 6 members of a family with the surface electrocardiographic features of the Lown-Ganong-Levine syndrome though the proband was studied by intracardiac electrical stimulation and found not to have the features of an atrioventricular nodal bypass tract. The present report is the first of identical twins each with electrophysiological evidence of an atrioventricular nodal bypass tract. In theory, patients with an atrioventricular nodal bypass tract should show no increase in AH interval with premature atrial stimulation. In practice, however, this is a rare finding and usually, as in our patients, small increases in $\mathrm{AH}$ interval do occur (Castellanos et al., 1971; Caracta et al., 1973; Wellens, 1975). The increase in AH interval in Twin B was greater than in Twin A and the former might be considered to have a 'partial' rather than 'complete' bypass tract. It should be pointed out that though the electrophysiological characteristics of an atrioventricular nodal bypass tract are well recognised there is doubt as to whether the tract is extranodal or intranodal and whether it is a functional rather than an anatomical entity (Wellens, 1975). Because of these doubts Gallagher et al.
(1976) prefer to use the term 'enhanced AV node conduction'.

A further point of interest was the differing forms of pre-excitation in the twins; Twin A having an accessory atrioventricular pathway in addition to an atrioventricular nodal bypass tract. Presence of the accessory atrioventricular pathway was concealed during sinus rhythm and it required very short cycle lengths to cause slight but sufficient prolongation of atrioventricular nodal bypass tract conduction so that it was slower than conduction along the accessory atrioventricular pathway and hence led to the appearance of delta waves. A similar case has been reported by Massumi and Vera (1971). One possibility to be considered is that the delta waves were the result of Mahaim fibres since an accessory atrioventricular pathway can be mimicked by a combination of an atrioventricular nodal bypass tract and Mahaim fibres (Brechenmacher et al., 1976). However, the normal HV interval during sinus rhythm, and the progressive increase in degree of pre-excitation and progressive shortening of the $\mathrm{HV}$ interval with decreasing cycle lengths (seen particularly in the second study) are against this possibility (Wellens, 1975; Gallagher et al., 1976). Nevertheless, as pointed out by Wellens (1975), Mahaim fibres inserted into the atrioventricular node in such a location as to bypass much of the part of the node responsible for causing delay in atrioventricular conduction might be indistinguishable from an accessory atrioventricular pathway. The demonstration of left atrial pre-excitation during ventriculoatrial conduction by recording a left atrial electrogram during ventricular pacing would have been helpful in supporting the diagnosis of an accessory atrioventricular pathway, and also in confirming that the pathway was left sided, as suggested by the type A delta waves (Wellens, 1975).

In Twin B no evidence of an accessory atrioventricular pathway was found. It is possible that this pathway was present but was only able to conduct retrogradely. Here again confirmation of this possibility would have required a demonstration of left atrial pre-excitation during ventriculoatrial conduction but even if an accessory atrioventricular pathway had been present ventriculoatrial conduction via the atrioventricular nodal bypass tract might have prevented left atrial pre-excitation.

In summary, identical twins with the same surface electrocardiographic signs of pre-excitation were found to have very different electrophysiological characteristics.

We are grateful to Dr R. Spurrell for advice about treatment and to Reckitt and Colman Pharmaceutical Division for supplying the amiodarone. 


\section{References}

Brechenmacher, C., Courtadon, M., Jourde, M., Yermia, J. C., Cheynel, J., and Voegtlin, R. (1976). Syndrome de Wolff-Parkinson-White par association de fibres atriohissiennes et de fibres de Mahaim (in French). Archives des Maladies du Coeur et des Vaisseaux, 69, 1275-1283.

Brodsky, M., Wu, D., Denes, P., and Rosen, K. (1977). Familial atrial tachyarrhythmias with short PR interval. Archives of Internal Medicine, 137, 165-169.

Caracta, A. R., Damato, A. N., Gallagher, J. J., Josephson, M. E., Varghese, P. J., Lau, S. H., and Westura, E. E. (1973). Electrophysiologic studies in the syndrome of short PR interval, normal QRS complex. American fournal of Cardiology, 31, 245-253.

Castellanos, A., Jr., Castillo, C. A., Agha, A. S., and Tessler, M. (1971). His-bundle electrograms in patients with short PR intervals, narrow QRS complexes and paroxysmal tachycardias. Circulation, 43, 667-678.

Gallagher, J. J., Sealy, W. C., Kasell, J., and Wallace, A. G. (1976). Multiple accessory pathways in patients with the pre-excitation syndrome. Circulation, 54, 571-591.

Harnischfeger, W. W. (1959). Hereditary occurrence of the pre-excitation (Wolff-Parkinson-White) syndrome with re-entry mechanism and concealed conduction. Circulation, 19. $28-40$.

Lown, B., Ganong, W. F., and Levine, S. A. (1952). The syndrome of short P-R interval, normal QRS complex and paroxysmal rapid heart action. Circulation, 5, 693-706.

McIntire, M. S., and Freed, A. E. (1955). The WolffParkinson-White syndrome-report of a case occurring in a mother and infant. American Fournal of Diseases in Children, 89, 743-747.
Massumi, R. A. (1967). Familial Wolff-Parkinson-White $\stackrel{\leftarrow}{\leftarrow}$ syndrome with cardiomyopathy. American fournal of Medicine, 43, 951-955.

Massumi, R. A., and Vera, Z. (1971). Patterns and mechanisms of QRS normalization in patients with Wolff-ParkinsonWhite syndrome. American fournal of Cardiology, 28, 541-554.

Oehnell, R. F. (1944). Pre-excitation, a cardiac abnormality. Chap. 9. Heredity in pre-excitation. Acta Medica Scandina- कै vica, Suppl. 152, 72-73.

Schneider, R. G. (1969). Familial occurrence of WolffParkinson-White syndrome. American Heart fournal, 78, 34-36.

Spurrell, R. A. J., Krikler, D., and Sowton, E. (1973). Two or more intra AV nodal pathways in association with either a James or Kent extranodal bypass in 3 patients with paroxysmal supraventricular tachycardia. British Heart Fournal, 35, 113-122.

Wellens, H. J. J. (1975). Contribution of cardiac pacing to our understanding of the Wolff-Parkinson-White syndrome. British Heart fournal, 37, 231-241.

Wolff, L., Parkinson, J., and White, P. D. (1930). Bundle: branch block with short P-R interval in healthy young people prone to paroxysmal tachycardia. American Heart fournal, 5, 685-704.

Requests for reprints to Dr David Bennett, Cardiac Department, Radcliffe Infirmary, Oxford OX2 6HE. 